\title{
Exploring NASA Human Spaceflight and Pioneering Scenarios
}

American Institute of Aeronautics and Astronautics

Joint Propulsion Conference

July 2015

Edgar Zapata

NASA Kennedy Space Center FL

Alan Wilhite

Wilhite Consulting Yorktown VA 


\section{Abstract}

- It is possible and desirable to consider many human spaceflight scenarios within many possible long term NASA budget contexts

- Reconnaissance in many directions

- Not necessary to firmly know the eventual direction to define the boundaries of life cycle costs

- Situational awareness

- Will show:

- Not necessary to define every part of a scenario

- A scenario exploration strategy of "that which remains"; i.e., consistency

- Merger of well-defined portions of content with well defined context as scenarios provides valuable insights for "that which remains"

- Defines the necessary affordability and productivity characteristics of "that which remains" 


\section{Introduction}

- The NASA Budget since 2003

- Context for any content

- Importance to understand past funds flow to understand possible futures

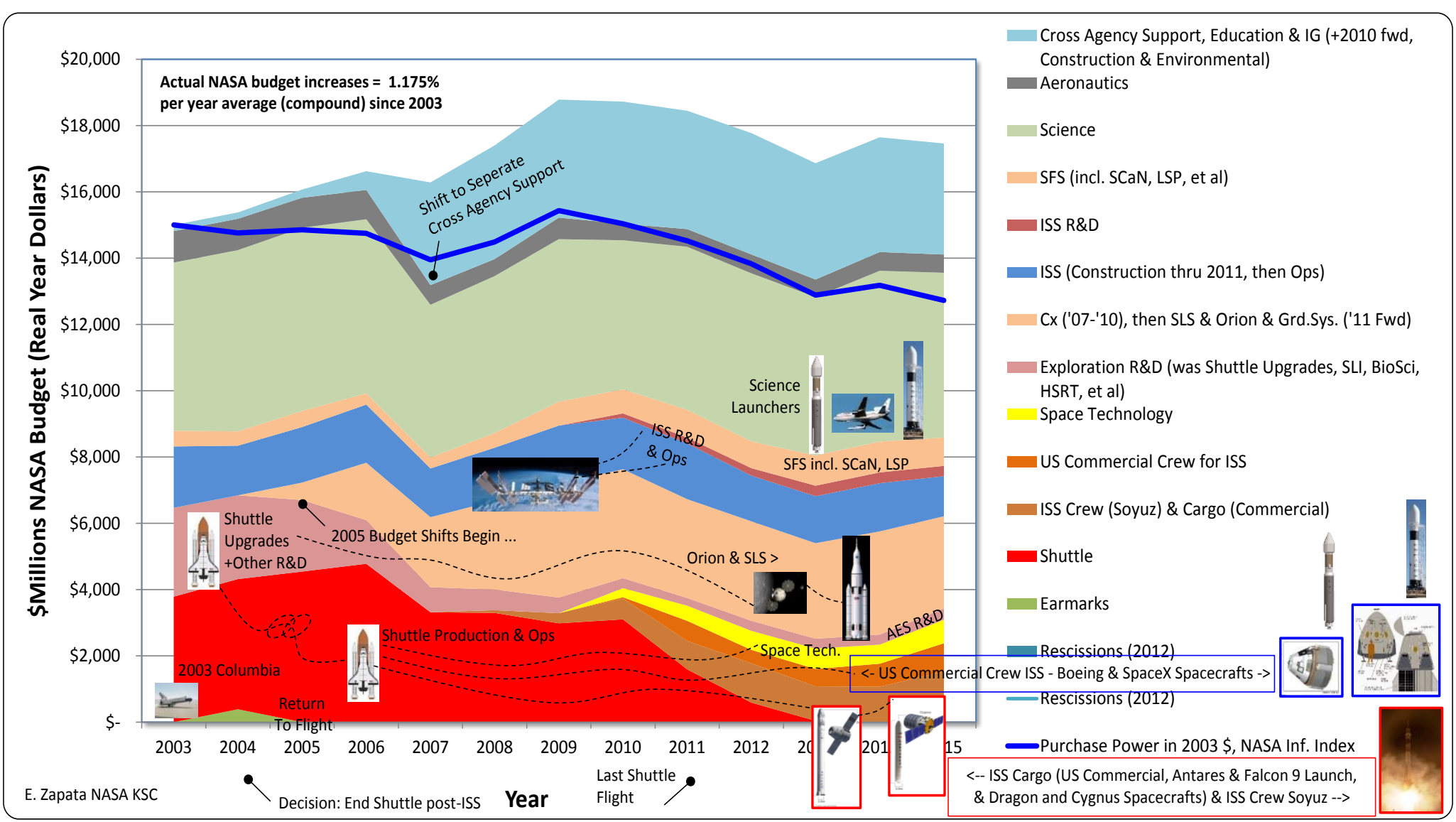




\section{Introduction}

- The NASA Budget since 2003

- NASA's budget has increased on average $\mathbf{1 . 1 7 5 \%}$ per year since 2003

- NASA's purchasing power has declined 15\% from 2003 to 2015

- The end of the operational portion of NASA's Space Shuttle program freed up for other purposes $\$ 860 \mathrm{M}$ in 2013 , two years after the Shuttle last flight, and less, $\$ 360 \mathrm{M}$ a year by 2015 ; heading to zero funds freed up

- Operational funds have remained operational -near to the dollar

- Standing capability / Space Flight Support costs more visible after the end of the Shuttle program

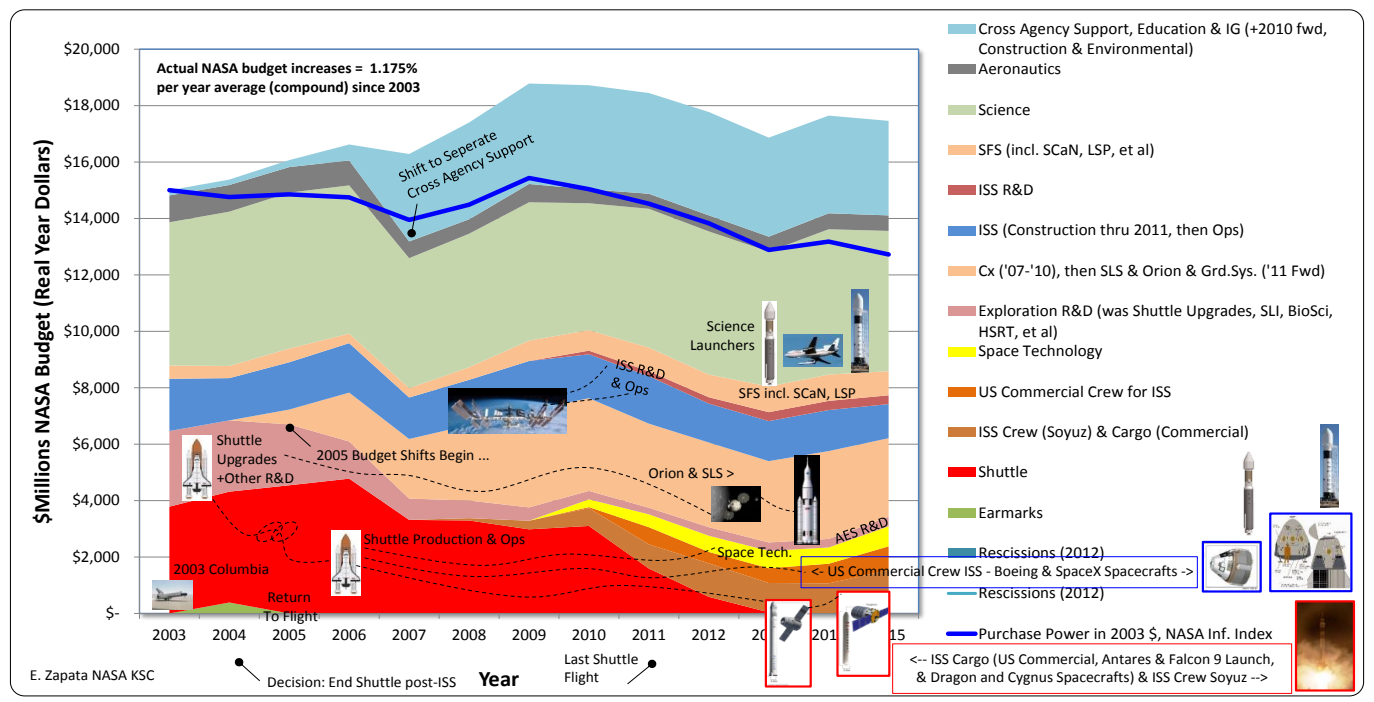




\section{Introduction}

- The future of ISS

2015 NASA Budget

- ISS Operations

- ISS R\&D, the use of the ISS

- ISS Cargo \& Crew, Transportation and Related Total International Space Station $=$

$\sim$ \$1.2 billion a year

$\sim$ \$300 million a year

$\sim 2.4$ billion a year

$\sim$ \$3.9 billion a year

- NASA ISS formal commitment through 2024

- Possibly "fine" through 2028

- After ISS? Private space stations - "we can just buy these services" from private sector space stations; "anchor tenant"

The Future of ISS = the Future of NASA's Presence in Low Earth Orbit 


\section{Introduction}

- Three factors drive the development of quantifiable NASA human spaceflight scenarios looking to the next decade

- Choices, pressures, technical and non-technical factors (economics, demographics, politics, societal trends and constraints, etc.) will affect specific content

- BUT-all the content and their interactions will manifest itself inside broad scenarios that are all about context

1. The growth rate of the NASA budget

2. The rate of cost inflation for the aerospace goods and services NASA acquires

3. The future of the International Space Station (ISS), or more broadly, the degree to which a human presence in low Earth orbit (LEO) persists in the NASA portfolio 


\section{Scenario Variable 1: NASA's Purchase Power}

- Locating the edges of the box

High Purchase Power Scenario: Average NASA budget increases 2016 forward are the same rate as the average cost inflation of the exploration \& operations goods and services. (Both 2.5\%).

Nominal Purchase Power Scenario: The NASA budget goes up yearly as it has in the past decade (1.175\%). Cost inflation as officially recommended in the NASA Inflation Index (2.5\%).

Low Purchase Power Scenario: The cost inflation of goods and services required by NASA increases an additional $1 \%$ above the recommended NASA Inflation Index (3.5\%). NASA yearly budget increases per recent historical data (1.175\%).
Why "High"? A "what-if", the NASA budget, increasing faster than supported by recent historical data.

Why "Nominal"? Both budget and inflation rate increases supported by historical trend data or official NASA sources. No "what-if".

Why "Low"? A "what-if", cost inflation, increasing faster than supported by official NASA sources. 


\section{Scenario Variable 2: Post-ISS Budget Availability}

- Locating the edges of the box

\begin{tabular}{|c|c|}
\hline $\begin{array}{l}\text { High post-ISS } \\
\text { Available } \\
\text { Funding } \\
\text { Scenario: }\end{array}$ & $\begin{array}{l}\text { Why "High"? A "what-if", funding freed-up for other uses post-ISS, disregarding wholly the } \\
\text { possibility of any continued NASA presence in LEO. } \\
\text { - Exception: ISS Operations as with Nominal (Mission Operations \& Control). } \\
\text { Sum=\$3,100M a year fully available }\end{array}$ \\
\hline $\begin{array}{l}\text { Nominal } \\
\text { post-ISS } \\
\text { Available } \\
\text { Funding } \\
\text { Scenario: }\end{array}$ & $\begin{array}{l}\text { Why "Nominal"? An extrapolation consistent with NASA statements. } \\
\text { - ISS Operations: } 1 / 3^{\text {rd }} \text { fully available, while other } 2 / 3^{\text {rds }} \text { also available, but limited to use } \\
\text { for (1) Mission Operations \& Control for Exploration and (2) Mission Operations \& } \\
\text { Management of NASA personnel aboard private LEO stations. (\$400M a year fully } \\
\text { available) } \\
\text { - ISS R\&D: Reduced } 50 \% \text { ( } \$ 150 M \text { a year fully available) } \\
\text { ISS Cargo \& Crew: Reduced } 50 \% \text { (private stations, NASA as "anchor tenant"); Station } \\
\text { owner handles in-their space operations and control. Reduction due to either less usage } \\
\text { and/or bundling/block services consistent with "services". } \\
\text { Sum=\$1,750M a year fully available }\end{array}$ \\
\hline $\begin{array}{l}\text { Low post-ISS } \\
\text { Available } \\
\text { Funding } \\
\text { Scenario: }\end{array}$ & $\begin{array}{l}\text { Why "Low"? As with Nominal, but "what-if" ISS Cargo \& Crew rides and related for a private } \\
\text { space station in an anchor tenant role are reduced only } 1 / 3^{\text {rd }} \text { from current levels. R\&D } \\
\text { remains at the same levels as today, but as NASA work occurring at private sector stations. } \\
\text { Sum=\$1,500M a year fully available }\end{array}$ \\
\hline
\end{tabular}




\section{Combining Scenario Variables}

- Examples

- The low and nominal post-ISS funding scenarios, combined with the nominal budget/inflation scenario, frees up zero (or negative) funding by the 2030's

- The high post-ISS funding scenarios, combined with the nominal budget/inflation scenario, will free up less than $\$ 10$ billion in funding by the late 2030's

- The high post-ISS funding scenario and the high purchase power scenario, allowing many 10's of billions of dollars in funding to be applied to exploration, Mars, etc. through the 2030s 


\section{Combining Scenario Variables}

- Context $=\mathrm{a}$ box with 3 sides

\section{"budget" X "inflation" X "future NASA LEO presence" Content Context}

Procurements

- Direct

- Indirect

- Space transportation

- Spacecraft (cargo, crew)

- Stages (departure, insertion)

- Habitats

- Landers

- Exploration vehicles

- Other elements (science, equipment, etc.)

- Ground operations/launch

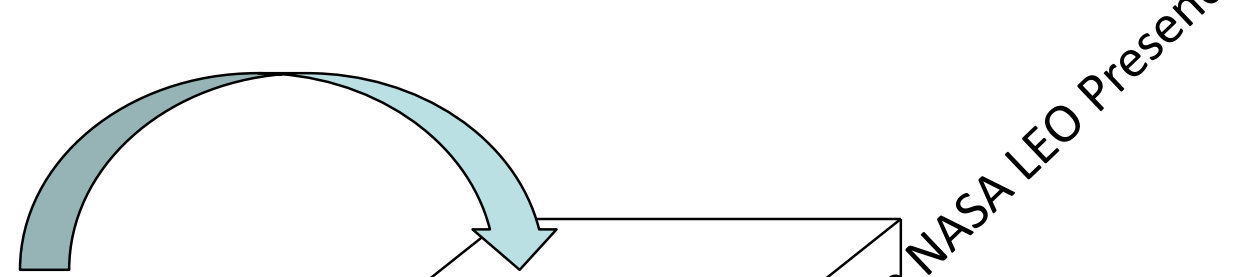

- Mission operations/control

- Other support (ScAN, etc.)

Government

- Program/project management 


\section{Cost Modeling, Historical Data}

- Older to Recent

- Cargo to Crew

- Cost+ to commercial

- For proposed scenario elements - preference for recent, commercial data

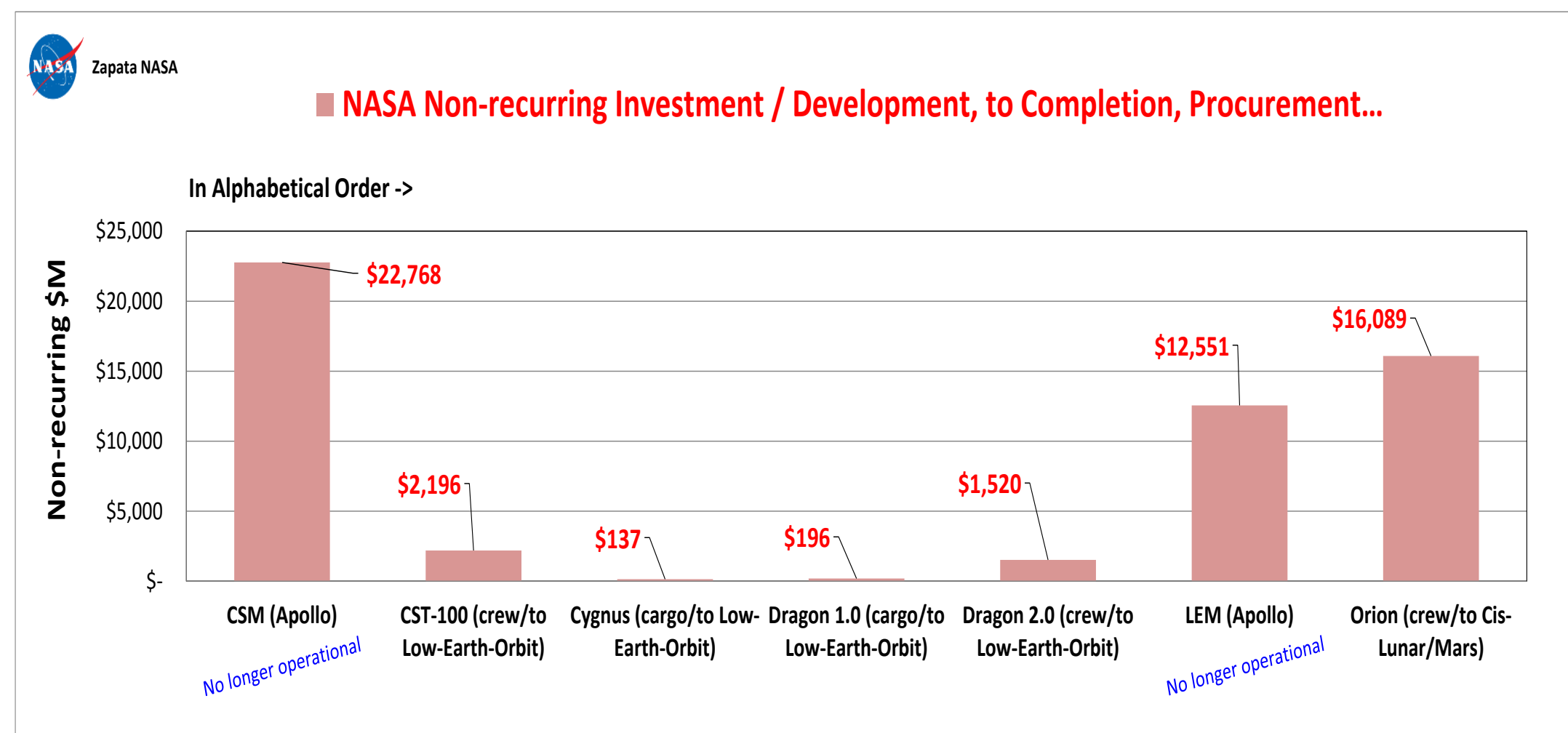

Spacecraft Comparison: Develop 


\section{Cost Modeling, Historical Data}

- Older to Recent

- Cargo to Crew

- Cost+ to commercial

- For proposed scenario elements - preference for recent, commercial data

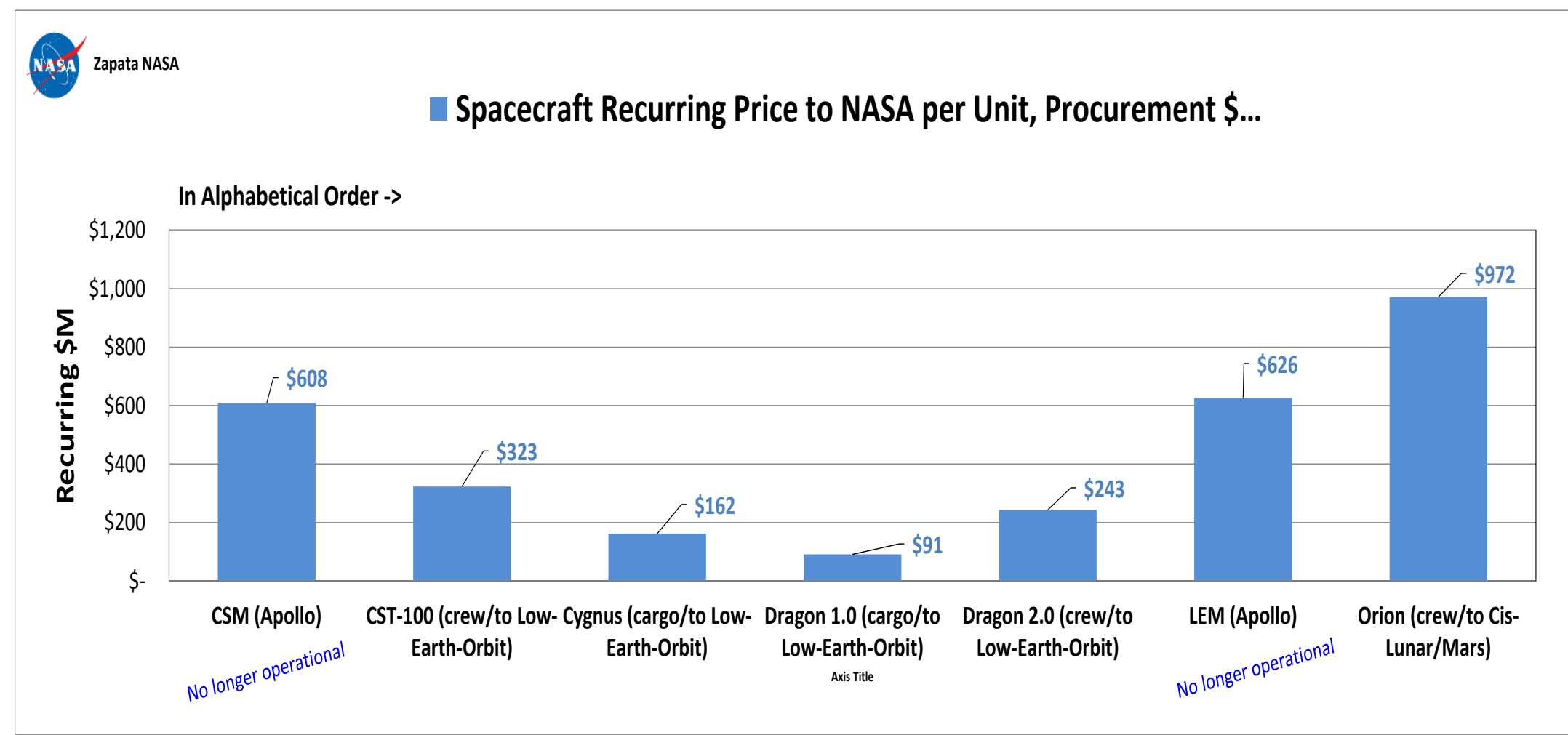

Spacecraft Comparison: Make -per unit 


\section{Scenarios}

- Canvas always the same

- What are the settings? Purchase Power, mission rate, elements?

- What is observed? Challenges? Overages?

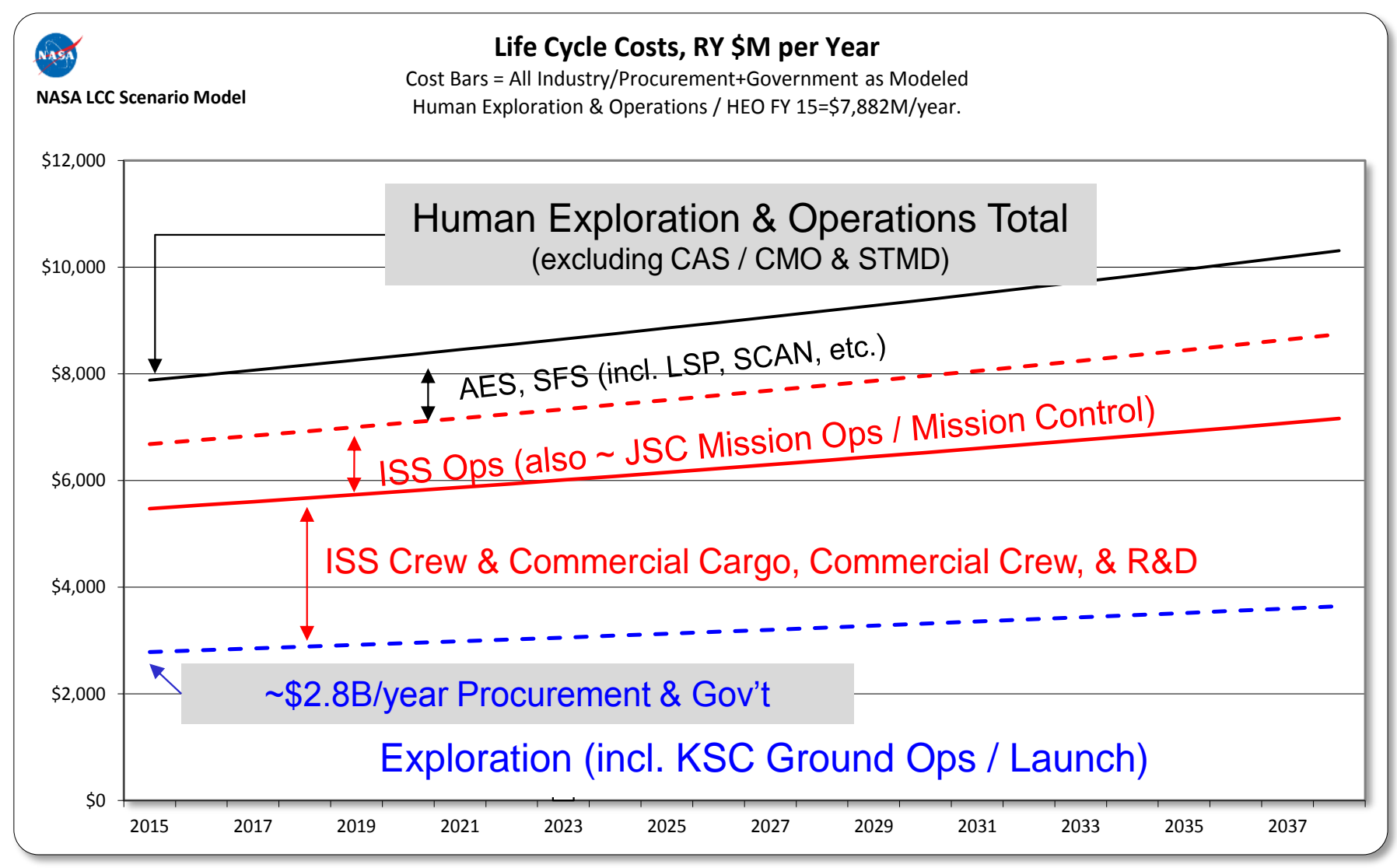




\section{The Interim Scenario - SLS (\& ICPS) - Nominal Purchase Power}

- Settings: Nominal Purchase Power, 2.0 missions/year

- Number of any launches per year: 2.0

- Observations: Challenges @ 2 flights/year (exceeds blue line 2022-2029); fits nominal \& high post ISS funding availability scenarios, but challenged at low

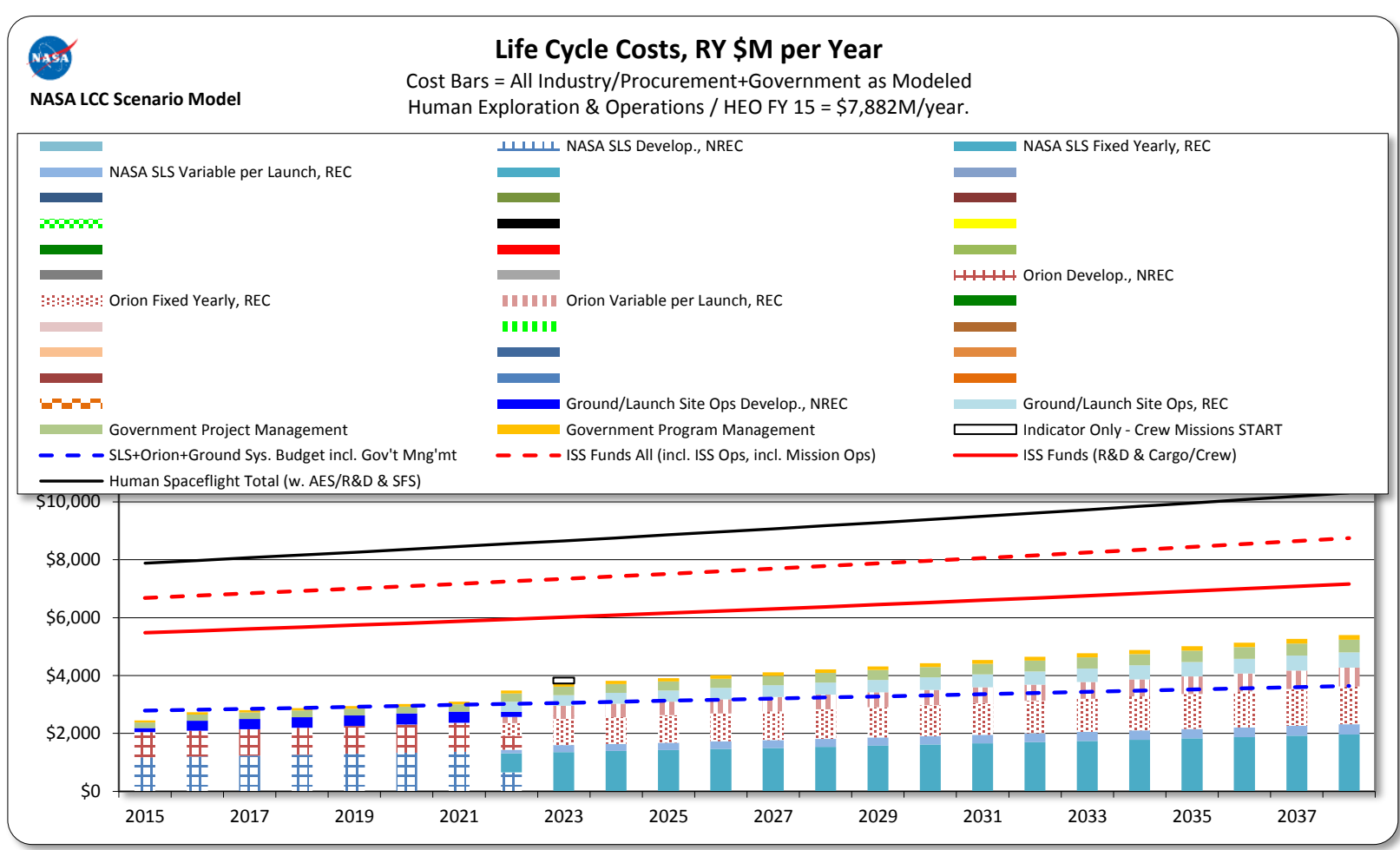

* SLS (minus ICPS) Fixed/variable costs based on Space Shuttle's documented "Zero Base*" costs (ET, SRB/SRM, Engines) per year; adjustments for accounting shifts, year dollars, larger core, addition of MPS, etc. 


\section{The Baseline Scenario - SLS (\& EUS), Orion - Nominal Purchase Power}

- Settings: Nominal Purchase Power, 2.0 missions/year

- Number of any launches per year: 2.0

- Observations: Challenges @ 2 flights/year (exceeds blue line 2022-2029); fits high post ISS funding availability scenarios, but challenged at low \& nominal

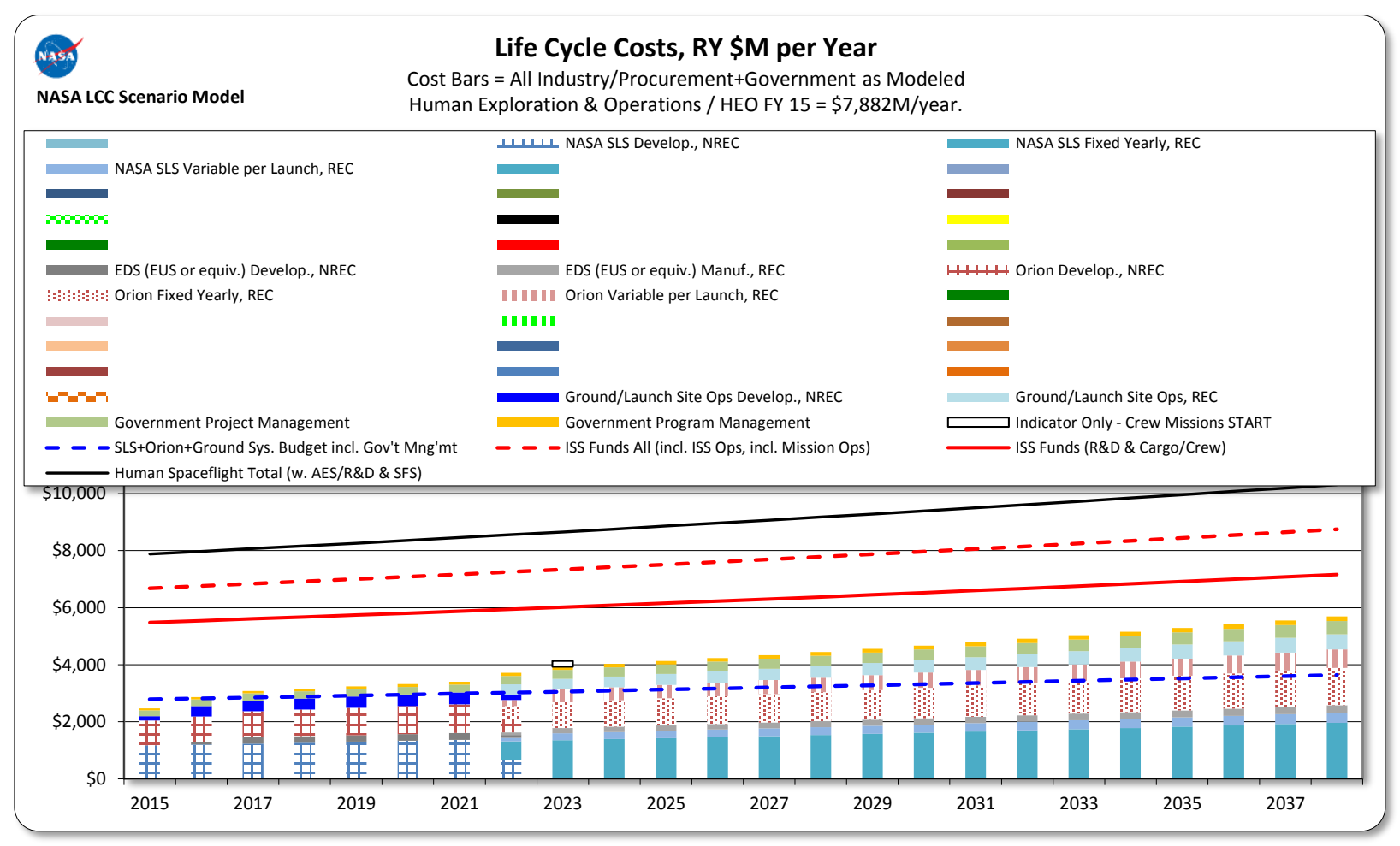




\section{The Baseline Scenario - SLS (\& EUS), Orion - High Purchase Power}

- Settings: High Purchase Power, 2.0 mission/year

- Number of any launches per year: 2.0

- Observations: Challenges @ 2 flights/year (exceeds blue line 2022-2029); fits all post ISS funding availability scenarios - leaves room for other elements (Mars, etc.) in high and nominal but little in low

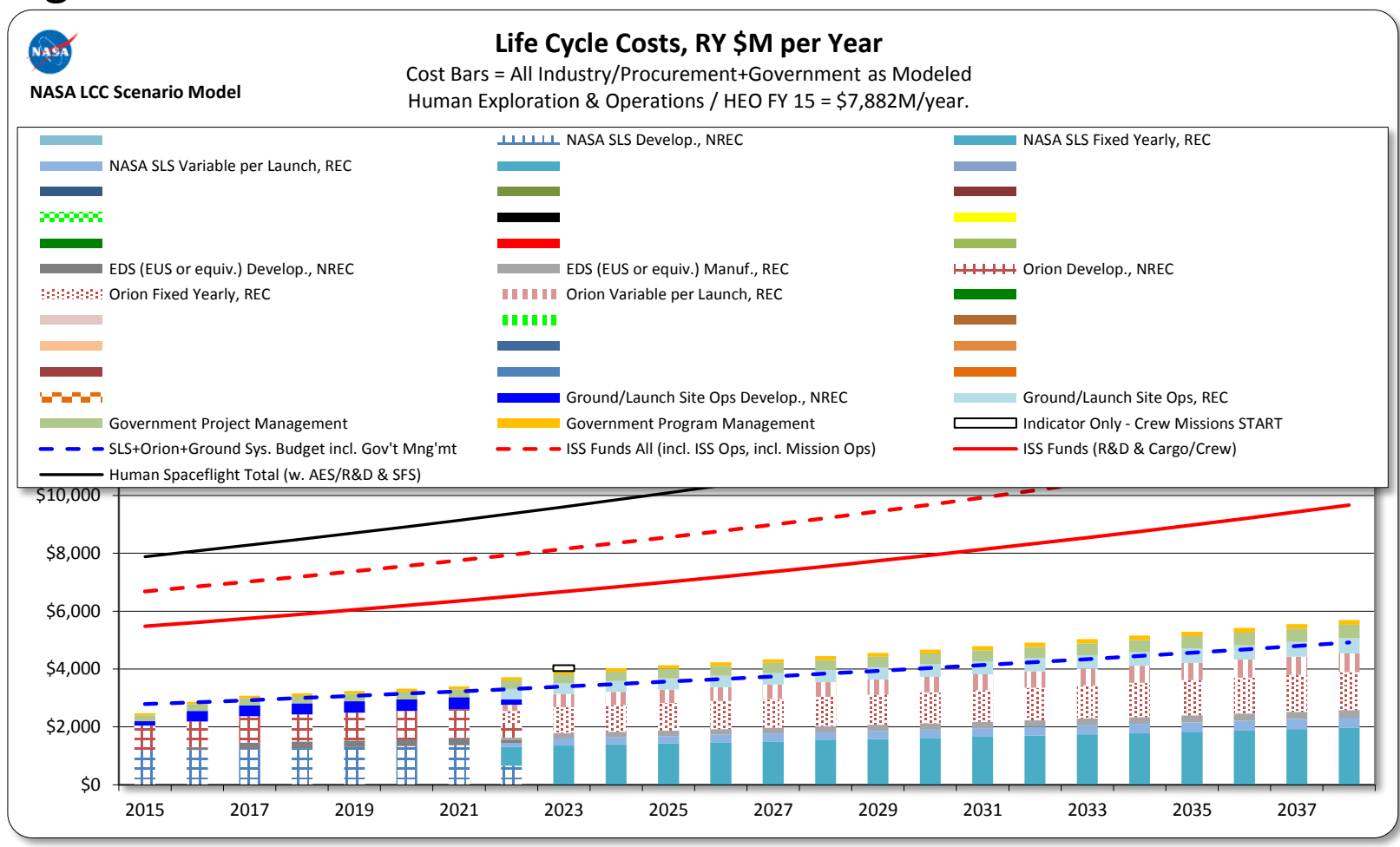




\section{The Baseline Scenario - SLS (\& EUS), Orion - Low Purchase Power}

- Settings: Low Purchase Power, 2.0 missions/year

- Number of any launches per year: 2.0

- Observations: More extreme challenges @ 2 flights/year (exceeds blue line 20222029); fits only high post ISS funding availability scenario - leaves no funding for other elements (Mars, etc.) post-ISS

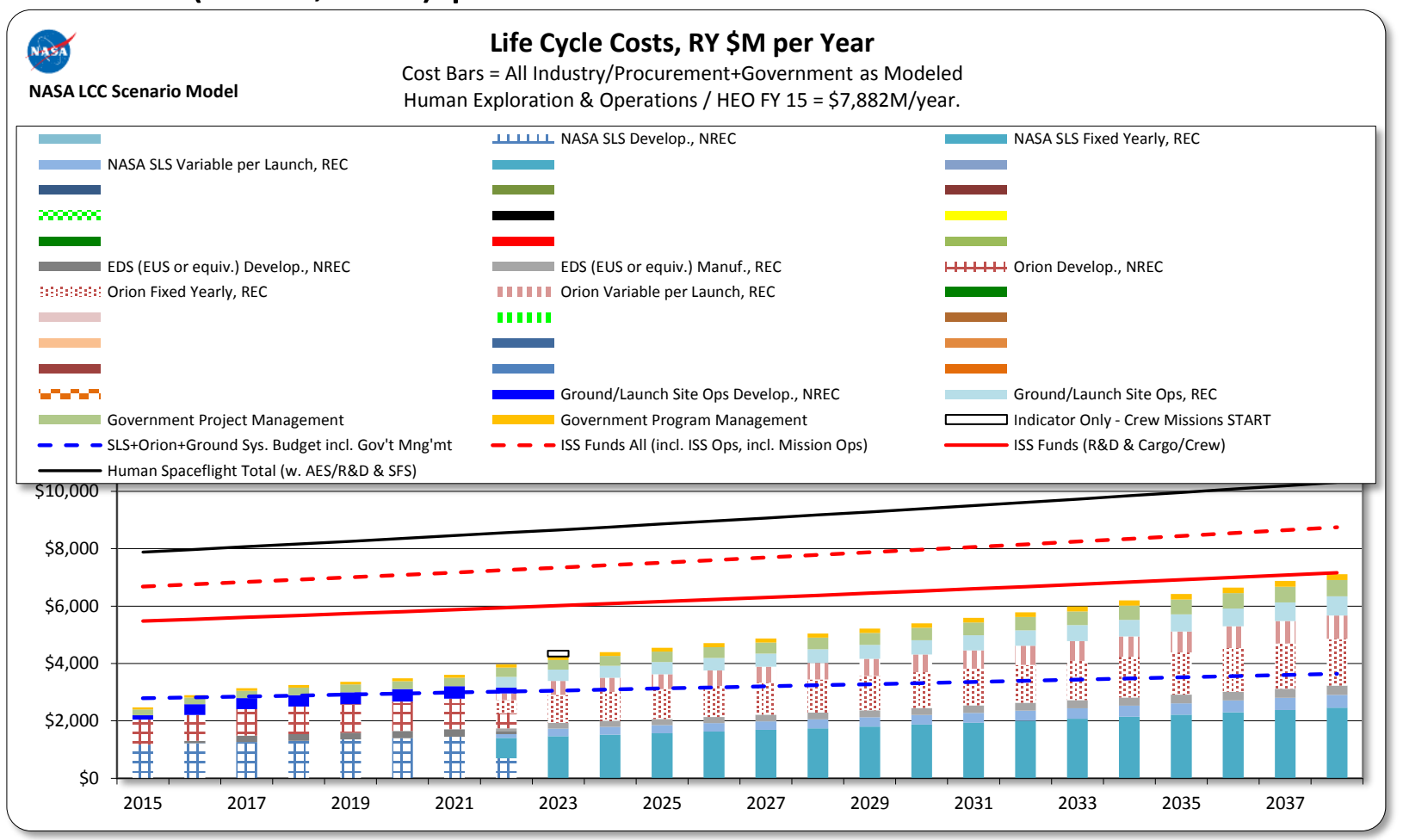




\section{Alternate Scenario 1 - Lunar via Commercial \& In-space Refueling}

- Settings: Nominal Purchase Power, 1.0 mission/year

- Number of any launches per year: 6.0 (4.0 are tankers)

- Observations: Assumes redirection, mixed fleet (ULA/SpaceX); commercial lander, 2 providers; commercial cis-lunar crew spacecraft; fits all post ISS funding scenarios - room for other elements (Mars, etc.) in high \& nominal but little in low

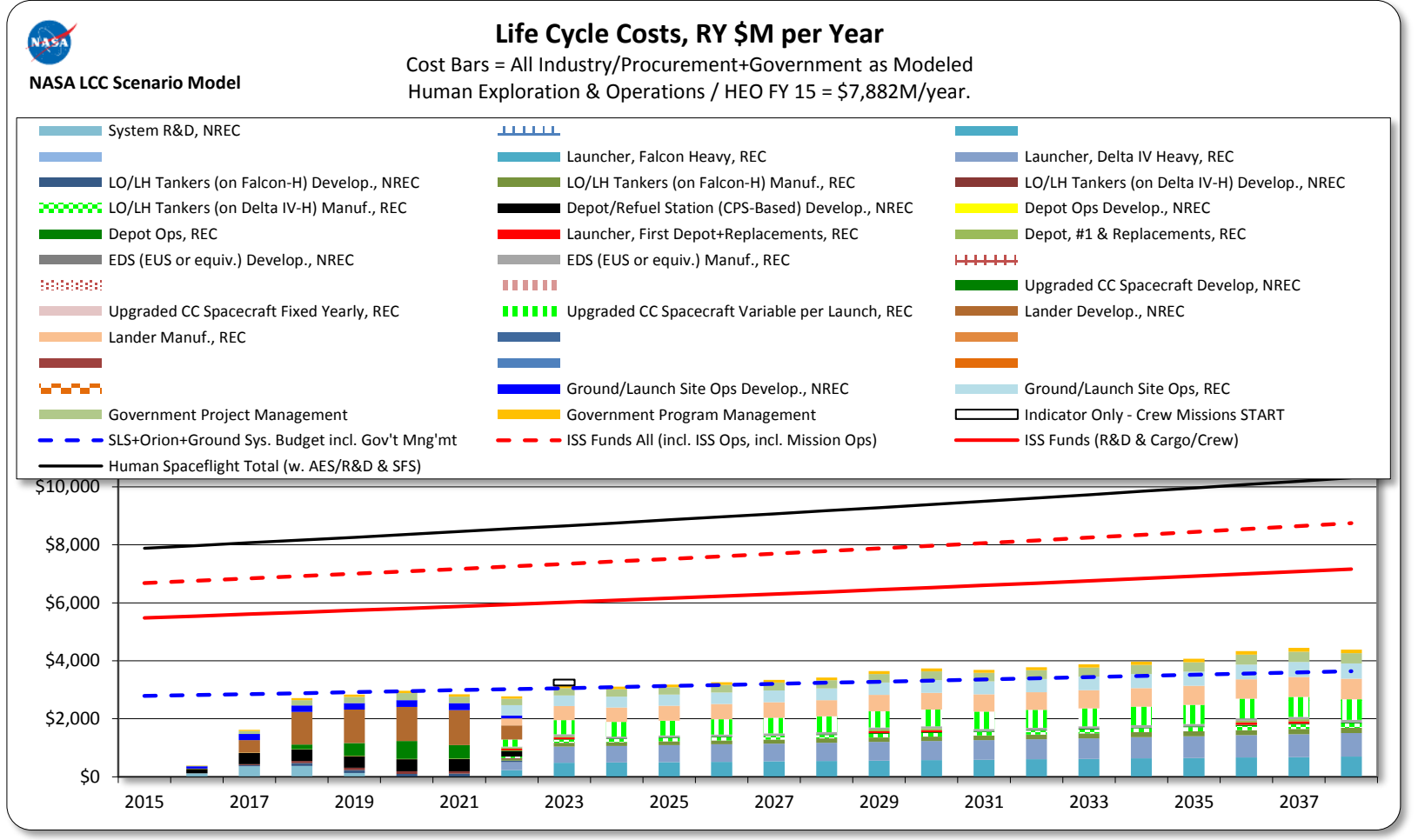




\section{Alternate Scenario 1 - Same as Prior - Lunar But FH Prices @ 2 providers}

- Settings: Nominal Purchase Power, 1.0 mission/year

- Number of any launches per year: 5.0 (3.0 are tankers)

- Observations: Same as prior, but requires that lightening strike twice, a $2^{\text {nd }}$ launch provider. Repeating NASA investment would not show (too small $\sim 200 \mathrm{M}$ to NASA)

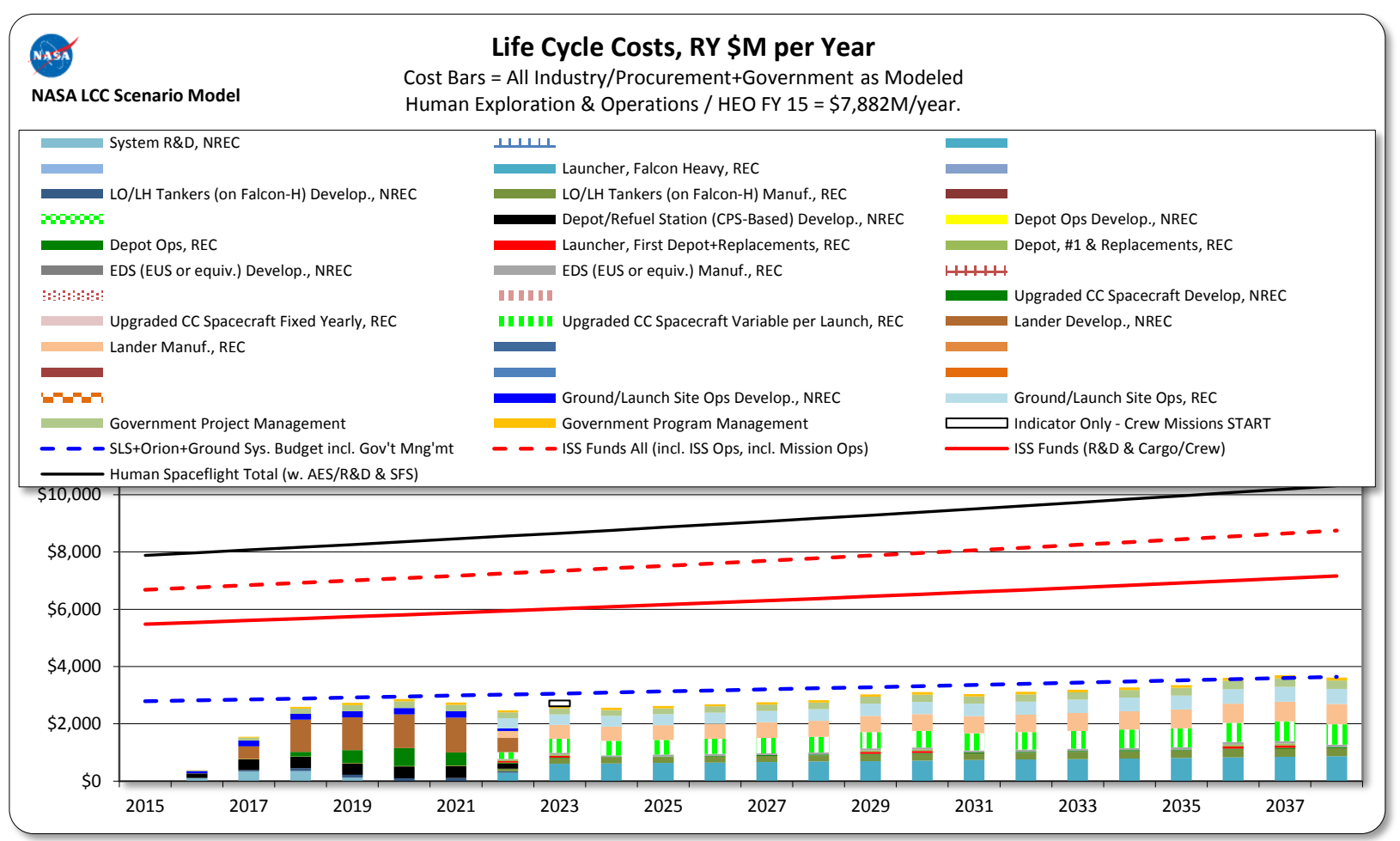




\section{"What-if" Scenario - SLS/EUS, Orion and a Mars "What-if 13/2.5"}

- Settings: Nominal Purchase Power, 1.0 missions every 4.5 years

- Number of any launches per year: 2.0

- Observations: Mars elements (excluding launch \& crew spacecraft) treated as a "what-if" of \$13B development, \$2.5B per mission set; does not fit low and nominal post-ISS funding scenarios, and challenged to fit low

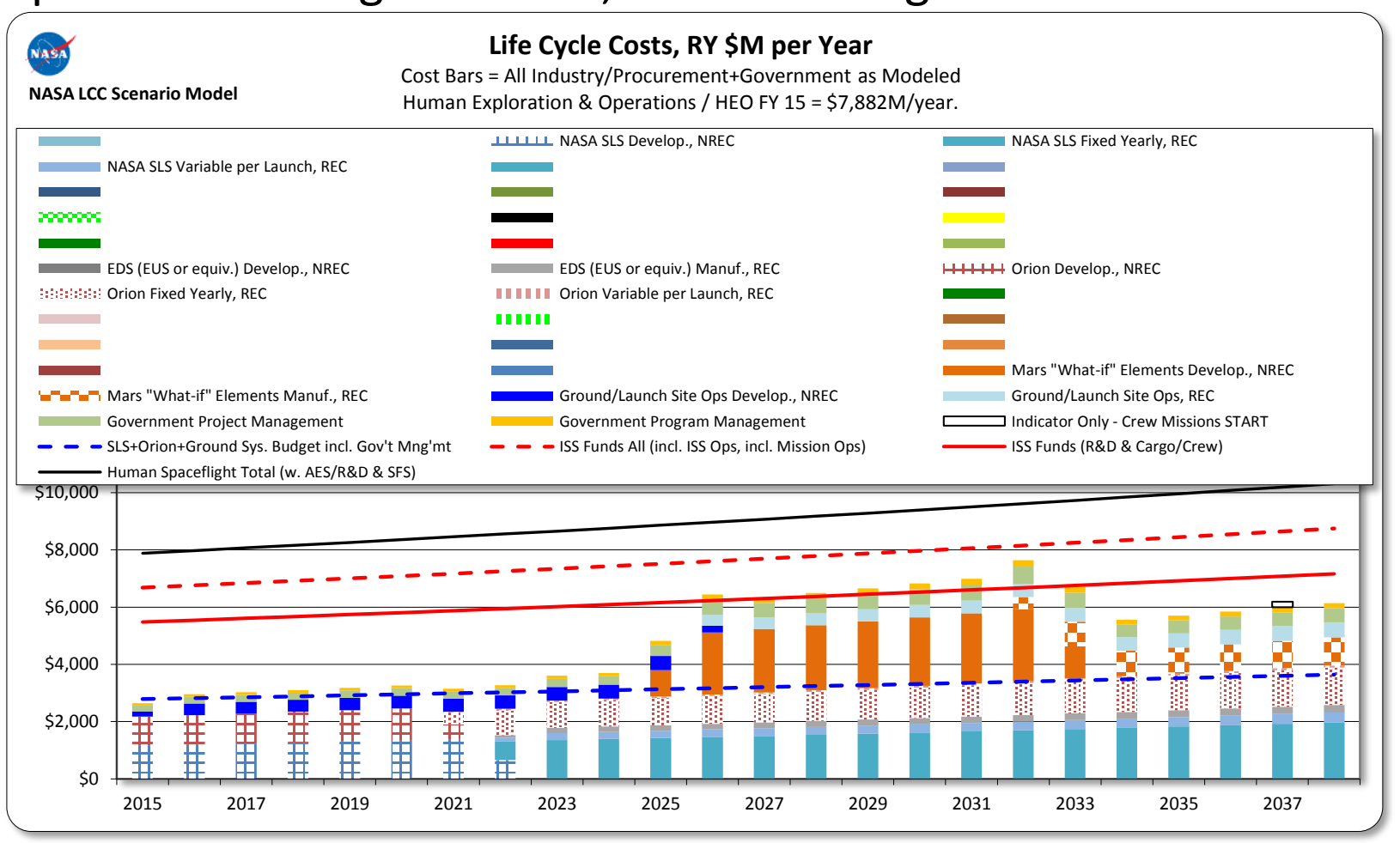




\section{"What-if" Scenario - In-Space Refueling and a Mars "What-if - 13/2.5"}

- Settings: Nominal Purchase Power, 1.0 missions every 4.5 years

- Number of any launches per year: 7.1 (5.1 are tankers)

- Observations: Mars elements same as prior; fit all post-ISS funding scenarios (as-if ISS or variant/private stations continue at current investment levels); challenges increasing mission rate to every 2 years, but plausible w. nominal post-ISS funding

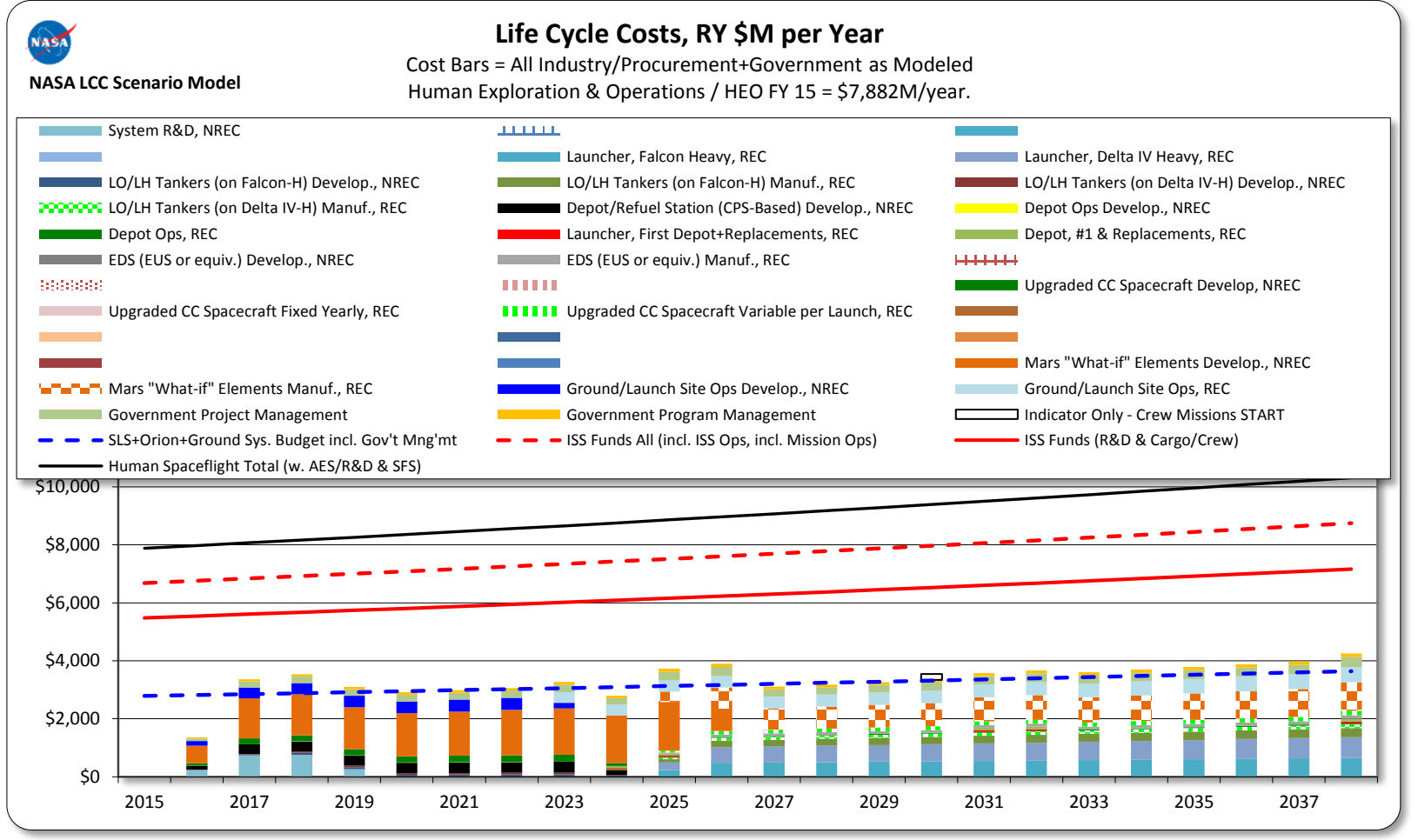




\section{Potential LEO Propellant Node (as applied in previous scenarios)}

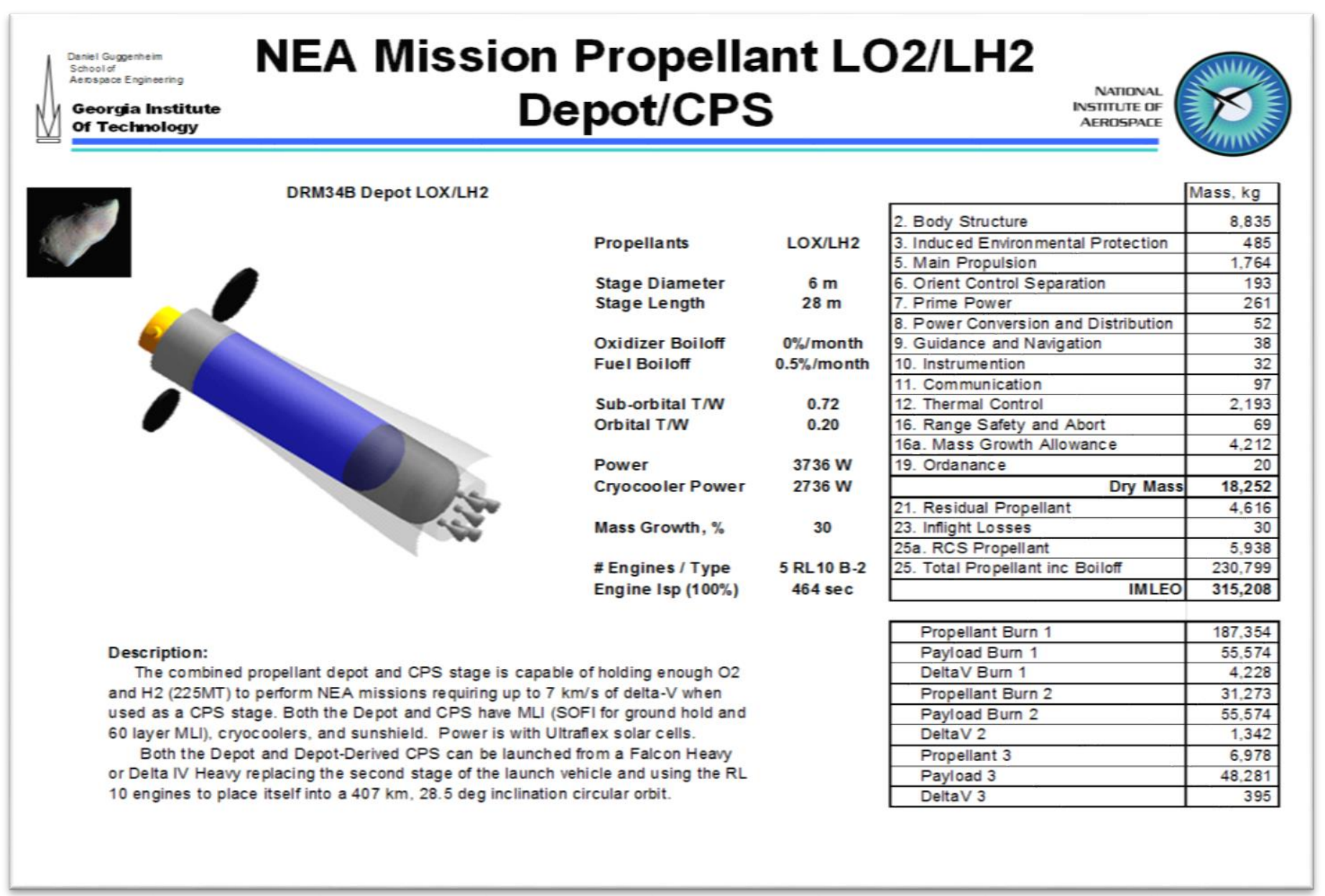

A Propellant Depot at a scale of an Earth departure stage applicable to a Design Reference Architecture 5.0 type Mars missions, among others. The commonality between a propellant depot and a cryogenic propulsion stage (CPS) would reduce their development costs while also having the basic manufacturing capability always active, through ongoing production of Earth departure stages, for when the depot requires replacement at the end of its design life.

Wilhite, A., Chai, P., "Plan B for U.S. Human Space Exploration Program," American Institute of Aeronautics and Astronautics, Aug.2014. pp.10. 


\section{The importance of the Scale of the Earth Departure Stage}

- From NASA DRA 2009

- Larger

- Smaller

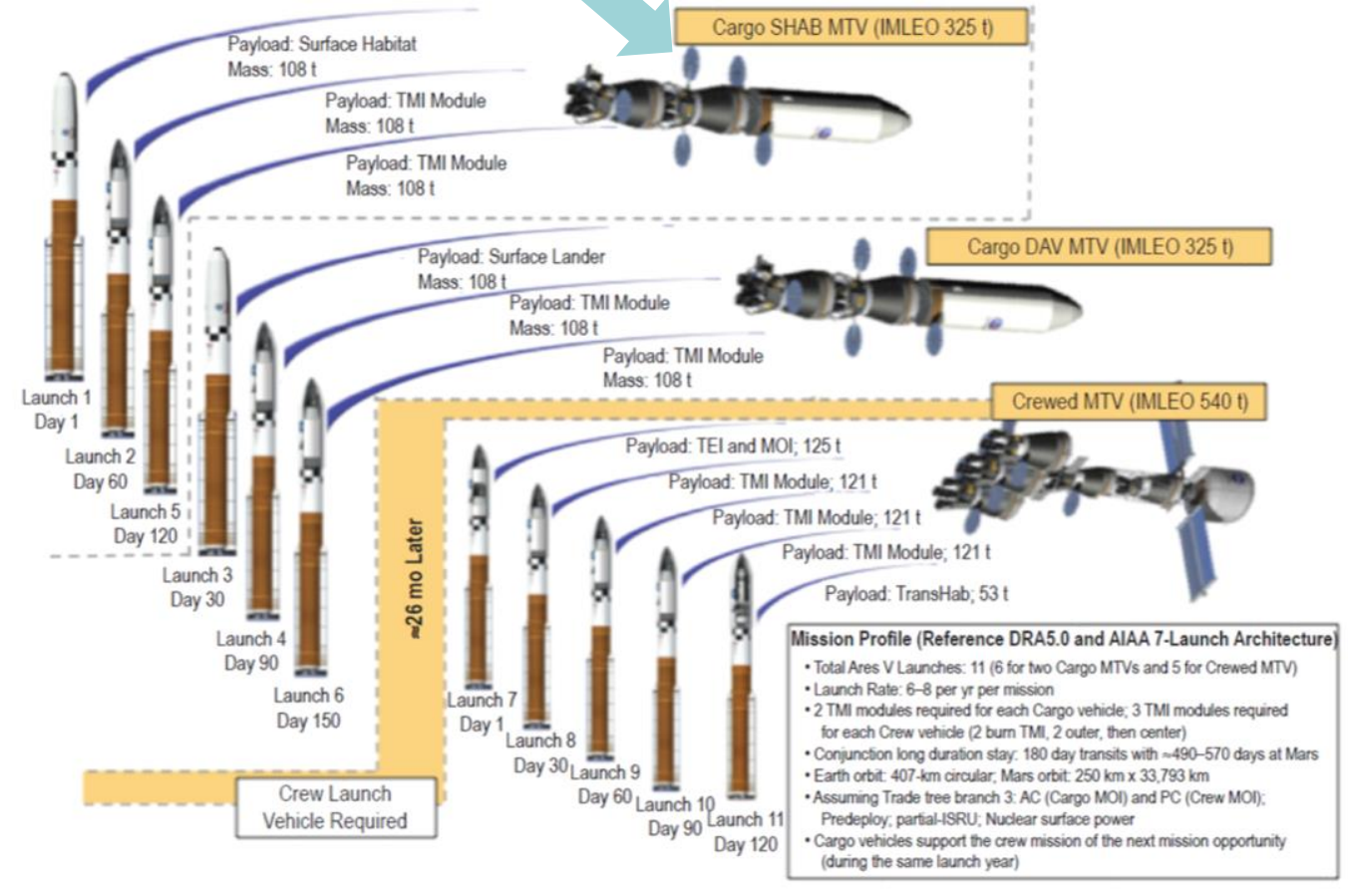

Poylows Propelint (Tanis TMII Stage and Deodes)

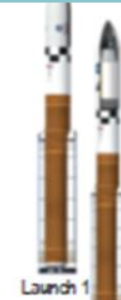

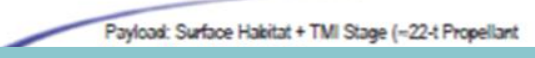

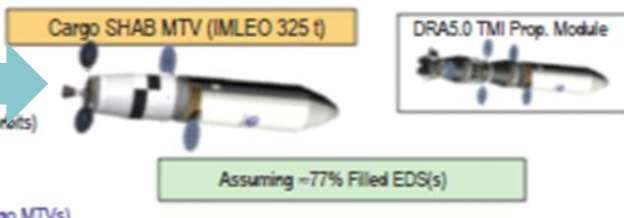

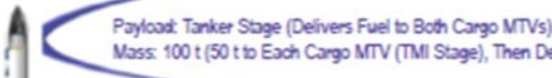

Assuming $=77 \%$ Filed EDS(s)
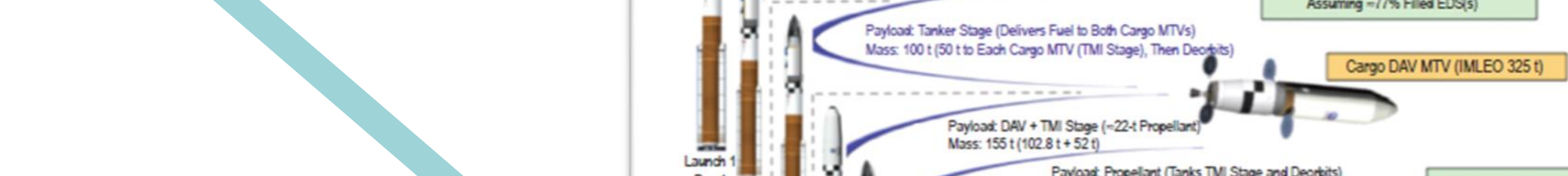

Payloost DAV + TVI Sbge (-22:t Propellont)
Mass: $155 \mathrm{t}(1028 \mathrm{t}+52 \mathrm{t})$
Paylout Propelont (Tanis TVI Sbge and Deortits)

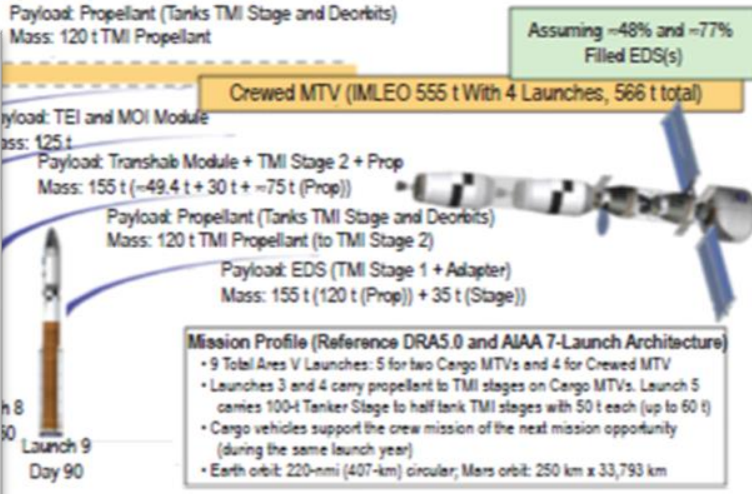




\section{"All Our Models Say No" - and Recommendations}

- Not here to select a scenario

"All our models say 'no,'" said Elizabeth Robinson, NASA's chief financial officer, "even models that have generous affordability considerations." 2011

- Change all the context?

- Asks that abundant factors in the world outside NASA change

- Change all the contents?

- Asks that abundant processes and programs inside NASA change

- ALL are non-linear scenarios, with breaks either built in or pending

- Abundant other "non-linear" scenarios left un-explored (events driven, the unexpected, failures, crew safety, etc.)

\section{What can we observe of value across this multi-verse of scenarios?}




\section{Recommendations}

Lower the height of the numerous cost $\$$ bars across the life cycle profiles, increase the mission rates, and sooner, for relevance

- Require all future Points of Departure for new elements be partnerships

- About degrees, not if/or

- Alignment of incentives

- Path to lowering development costs simultaneous with lower per unit manufacturing and ground/mission operations costs

- Consistent with improving purchase power regardless of budget scenario

- Require productivity goals that continuously go up, while still fitting context, not down (less for less)

- True "pioneering" goes well beyond exploring; this recommendation is consistent with seeking "pioneering" outcomes

- Require NASA acquisitions to favor systems and partners that also grow nonNASA business

- Amortize costs of element development and maintaining production lines over more customers; lower costs through efficiency, alignment of incentives 


\section{Recommendations}

Lower the height of the numerous cost $\$$ bars across the life cycle profiles, increase the mission rates, and sooner, for relevance

- Require increasing reusability of elements

- Less make, less launch of what was made

- Consistent $\mathrm{w}$. prior recommend addressing maintaining manufacturing lines

- Develop refueling capabilities and infrastructure

- If spaceships are to be reused, they will need to be refueled

- Mars (and the solar system) via the Moon, ISRU

- Budget efficiencies (from reuse of emplaced assets, amortizing over many uses) \& mass (IMLEO) efficiencies 


\section{Conclusions}

- Analysis demonstrated the possibilities and importance of merging context and content

- Made possible by merging cost modeling, analysis and scenario planning

- Demonstrated how to avoid the tension between the details and numbers for specific paths and being overwhelmed when stepping back to consider all the possibilities

- Future applications - a "sequel" - will mature this capability and develop more scenarios, emphasizing the recommendations 